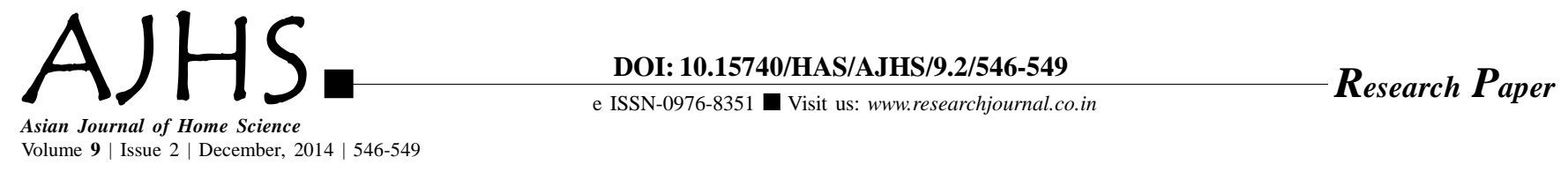

\title{
Natural dye from traditional medicinal source: mulethi
}

\author{
ANKITA SHARMA, ARCHANA SINGH AND SUMAYAL ANJUM
}

Received: 05.09.2014; Revised: 09.11.2014; Accepted: 24.11.2014

See end of the paper for authors' affiliations ANKITA SHARMA

Department of Textiles and Clothing, College of Home Science, Chandra Shekhar Azad University of Agriculture and Technology, KANPUR (U.P.) INDIA
ABSTRACT : With the growing importance and popularity of concepts like green, eco-friendly, sustainability, etc. natural dyes seems to have become an obvious choice for enlightened producers and consumers of textiles. There is a great demand for natural dyed products in foreign countries as well as in India. Cotton fabric dyed with natural dyes in soft and subdued shades with traditional designs creates a fashion statement. In this view the present research work has been taken on standardization of dyeing process for cotton with natural dye extracted from mulethi (Glycyrrhiza glabra).

KEY WORDS: Natural dyeing, Mulethi, Cotton, Mordant

n HOW TO CITE THIS PAPER : Sharma, Ankita, Singh, Archana and Anjum, Sumayal (2014). Natural dye from traditional medicinal source: mulethi. Asian J. Home Sci., 9 (2) : 546-549. 